\title{
Discipline in Thermodynamics
}

\author{
Adrian Bejan \\ Department of Mechanical Engineering and Materials Science, Duke University, Durham, NC 27708-0300, USA; \\ abejan@duke.edu
}

Received: 24 April 2020; Accepted: 11 May 2020; Published: 15 May 2020

check for updates

\begin{abstract}
Thermodynamics is a discipline, with unambiguous concepts, words, laws and usefulness. Today it is in danger of becoming a Tower of Babel. Its key words are being pasted brazenly on new concepts, to promote them with no respect for their proper meaning. In this brief Perspective, I outline a few steps to correct our difficult situation.
\end{abstract}

Keywords: thermodynamics; discipline; misunderstandings; disorder; entropy; second law; false science; false publishing

\section{Our Difficult Situation}

Thermodynamics used to be brief, simple and unambiguous. Today, thermodynamics is in a difficult situation because of the confusion and gibberish that permeate through scientific publications, popular science, journalism, and public conversations. Thermodynamics, entropy, and similar names are pasted brazenly on new concepts in order to promote them, without respect for their proper meaning.

Thermodynamics is a discipline, a body of knowledge with unambiguous concepts, words, rules and promise. Recently, I made attempts to clarify our difficult situation [1-4], so here are the main ideas:

The thermodynamics that in the 1850s joined science serves now as a pillar for the broadest tent, which is physics. From Carnot, Rankine, Clausius, and William Thomson (Lord Kelvin) came not one but two laws: the law of energy conservation (the first law) and the law of irreversibility (the second law). The success of the new science has been truly monumental, from steam engines and power plants of all kinds, to electric power in every outlet, refrigeration, air conditioning, transportation, and fast communication today.

Yet, as soon as the two laws were announced, scientists sought to shoehorn the new science into the old mechanics doctrine. The first law was easy, as was already known in mechanics since the early 1700 s as vis viva and vis mortua, the conservation of kinetic energy into gravitational potential energy, and vice versa (that is, if we put it in today's thermodynamics terminology).

More difficult was the second law. The race was on to "deduce" the law of irreversibility from mechanics. Even the founders of thermodynamics (Rankine, Clausius, Kelvin) were persuaded to think that perhaps irreversibility is due to mechanics at infinitesimal scales, tiny whirls and particles, in the reductionist belief that infinitesimally small means fundamental.

The narrative that prevailed from these efforts came one generation after the founders, from Boltzmann, who reduced thermodynamics to a single system (closed, in equilibrium, inhabited by innumerable identical particles) and, surprise, an entirely new concept that did not exist in thermodynamics before: the probability of energy states.

The rest is history, or rather cacophony. There are many "entropies" in circulation now. Most scientists teach that the second law is "probabilistic", and that Boltzmann invented entropy. Reality is not that, and we can count on reality because nature is the same as it ever was. 
One entirely new concept (irreversibility, in thermodynamics) was replaced by another new concept (probabilities), from statistical mechanics. This sleight of hand has retarded physics because it has obscured the fact that thermodynamics is immensely more general and more applicable than statistical mechanics. Why so, because the object of thermodynamics is the "any system" (with any imaginable boundary, any interactions, and any constitution), whereas the object of statistical mechanics is narrow, with specified boundary, interactions and contents.

Statistical mechanics has its own big merits, which are not being questioned here. The point is that the utmost generality of thermodynamics is why today we have power plants, vehicles, cheap electric power, refrigeration, and practically instant travel and communications all over the globe.

The "cheap power" is the hand of freedom in the evolution of the configurations of the contrivances made by and attached to humans. The time direction of this evolutionary phenomenon is the same as that of "any" evolution, human-related or not human-related, bio or non-bio, past or future, small or large, and so on. Evolution is the universal phenomenon of change in configuration, in a discernible direction versus time. As physics, evolution is the physical ability of the system to exhibit change [1]. This physical feature is underpinned by the constructal law and the universal physical property of freedom.

"Phenomenon" is a set of distinct observations of the same kind, which repeat themselves in the billions. For example, the phenomenon of "having weight" (gravitas in Latin, and gravidam for being pregnant) is called gravity. The phenomenon of flowing "one way" is called irreversibility, as in the flow of water under the bridge, and the flow of a heat current from hot to cold. In thermodynamics, this universal phenomenon of irreversibility is the second law, even though in the original statements (Clausius, Kelvin) it was said in terms of heat flow and the production of mechanical work while a closed system is in communication with two temperature reservoirs.

\section{Entropy}

Entropy change (not "entropy") is a mathematical expression formulated by Clausius in order to show the irreversibility of "any" process (any change of state) experienced by any system. This way, the second law is an inequality. The measurement of the severity of the inequality sign is the entropy generated during the process, and this is being used as a measure of how irreversible (dissipative, imperfect) the process is.

Distinct from irreversibility is the phenomenon of order or disorder, construction or destruction, complexity or simplicity, organization, design, emergence or extinction, and many more such terms. This is the phenomenon of evolution in general, as physics [1]. Evolution is everywhere: river basins, aircraft models, turbulence, lungs, heat exchangers, urban traffic, and architecture. Observations of evolution reveal the physics of time in human perception [5] and the direction of time [6], which, as commanded by the constructal law [1,7], orients the evolution toward new configurations through which the flowing is easier.

According to Clausius, the second law is a piece of text, not mathematics: "No process is possible whose sole result is the transfer of heat from a body of lower temperature to a body of higher temperature." It is common sense, not jargon. It is a general statement that says nothing about entropy and disorder. Second law statements in terms of disorder, information or entropy death hold for significantly narrower fields. By the way, "information" comes from the Latin verb informo-informare, which means to give form and shape, to form, and to fashion. This is design "change", said the old fashion way, and it calls for greater attention to be paid to the universal phenomenon of design evolution in nature [1].

\section{Misunderstandings}

Misunderstandings circulate around "entropy" as a derived thermodynamic property. Here are just a few of the examples that I detailed in Refs. [1-4]: 
The second law explains evolution: This is not the case because the second law refers to any system, which is a black box without a specified configuration. "Evolution" is not that: it is the sequence of changes in configuration, with a discernible direction in time. The direction is discernible to the thinking mind of the observer, to whom and from whom all good science comes.

The arrow of time is the second law: This view is inspired by Clausius' example of an isolated system (the universe) the destiny of which is "nothing moves", or the entropy death. That view is blind to the flow configurations that form and evolve en route to that end. The time direction of evolution is another law, the constructal law: "For a finite size flow system (not infinitesimal) to persist in time (to live), it must evolve with freedom such that it provides easier and greater access to what flows." $[1,7,8]$.

Disorder is increasing: The fact is that "order" is in the eye of the observer. I see it happening everywhere and all the time. You can see it by looking at the birth and evolution of the large-scale structure of a turbulent jet or plume. Sure, each individual is unique: some of us are fascinated by the complications (the diversity), and some of us marvel at the organization, and question the principle.

Clausius' second law says nothing about disorder. The confusion stems from statistical mechanics and the example of an isolated box filled with particles the assembly of which tends toward a larger number of probable states, and from this the notion that the second law is "probabilistic". Strange, if I do not see or imagine contrast, and if I cannot make a drawing of that mental viewing, how can I speak of "order" and "disorder"?

To assume a swarm of particles in a closed box is to throw away the "any system" power of thermodynamics. The "any system" is the most general system, and the box with particles is the extremely special, local (ad-hoc), a bag with claimed contents but no discernible configuration.

Organization is governed by a maximum or minimum principle: This is confusing because to minimize entropy generation is not the same as to maximize entropy generation. The word "entropy" appears in such discussions and leaves the false impression that the second law accounts for entropy generation minimization and maximization. Reis [9] showed that the contradictory statements of extrema and optimality are ad-hoc consequences of the constructal law.

Even in an isolated system that proceeds toward its death according to the second law, the natural emergence of "order" and evolution is plain to see [3]. For example, in an isolated system filled non-uniformly with fluid (high pressure on one side of a partition, and low pressure on the other side), the birth and evolution of macroscopic organization are visible to the naked eye as the large-scale structure of turbulence, jets, wakes, and eddies. You can make drawings of these images.

Although one example is enough, here is a second: an isolated system contains two bodies, one with positive charge and the other with negative charge. On its way to second-law death, the isolated system impresses the observer with lightning, which is a macroscopic tree-shaped flow that speaks of order, organization, and evolution. You can take photographs of the lightning tree. There are innumerable examples [1], and refute the notion that the second law accounts for evolution. In physics, the evolution phenomenon is constructal law, not second law.

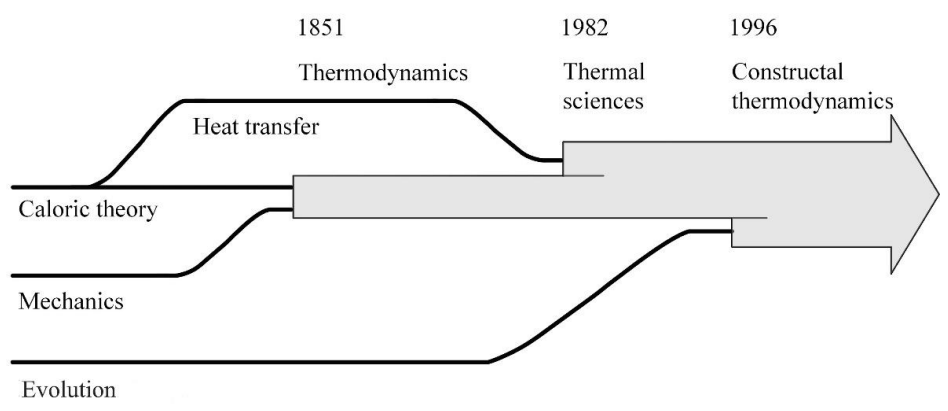

Figure 1. The evolution and spreading of thermodynamics during the past two centuries (Ref. [1]). The sources for the timeline are available in Refs. [2,7]: 1850-1851, the first papers by Rankine, Clausius and Kelvin; 1982, the first book on entropy generation through heat and fluid flow [10]; 1996, the first papers on constructal law. The first version of this figure appeared in 1982 [10]. 
The laws of thermodynamics hold only for closed systems: The laws of thermodynamics are universally valid, for any system. It is true that during the birth of thermodynamics (Figure 1) the system contemplated by the pioneers was closed: the heat engine operating in cycles or in steady state while in communication with two temperature reservoirs (Figure 2). The laws were generalized for open systems in the late $1800 \mathrm{~s}[2,7]$.

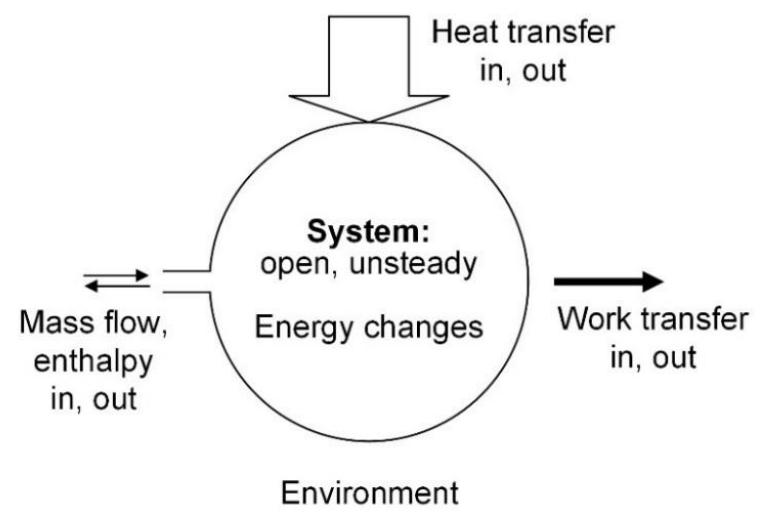

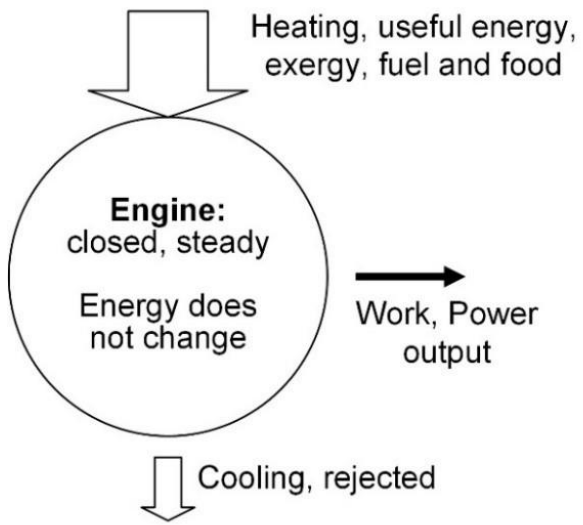

Environment

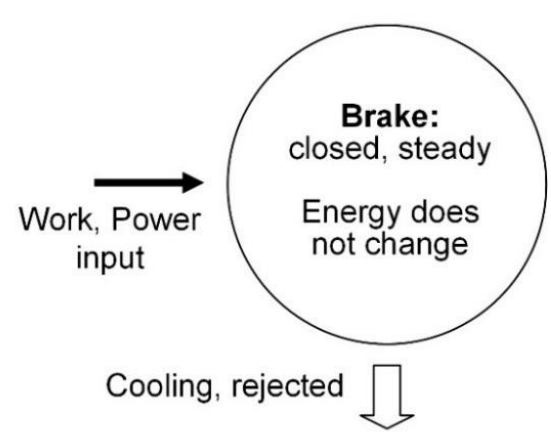

Environment

Figure 2. Nature is in the eye of the observer: it consists of just two systems, the system selected by the observer for analysis and discussion, and the rest, which is called the environment or the surroundings, also selected by the observer. Separating the two parts is the system boundary, which is chosen by the observer. Top: an open system can experience mass flow, heat transfer and work transfer across its boundary. A closed system cannot experience mass flow, because its boundary is impermeable. Bottom: two classes of closed systems in steady state (not changing in time): engines and brakes, or purely dissipative systems [1].

The laws of thermodynamics pertain to equilibrium states: The presence of the inequality sign in the second law contradicts this claim. The inequality sign refers to the irreversibility of flows driven by non-uniformity, or differences in pressure, temperature or chemical potential.

Analogy between heat and work. The claimed analogy between heating a solid body and charging an electrical capacitor [11] violates the second law. This misstep was red-flagged independently by a growing number of authors [12-19]. Yet, "new" thermodynamics is being promoted based on this 
analogy. This false claim is contrary to nature because heating a system is by heat transfer, and charging a capacitor is by work transfer.

The difference between heat transfer and work transfer is the second law: heat transfer is accompanied by entropy transfer, and work transfer is not accompanied by entropy transfer. This is why work does not appear as a term in any second law statement.

The cacophony generated by the heat-work analogy is fueled by its mathematical formulation, which makes extensive use of a supposedly new property, "entransy", invented to look and sound like "entropy", for instant legitimacy apparently. For the origin of this current, see Figure 3 here, and page 2546 in Ref. [11]. To discuss the critiques [12-19] is not necessary. Look instead at Figure 3, which shows the first two drawings that appeared in Ref. [11]. The two electrical capacitors were drawn to look like the single thermal capacitor shown above. The caption of the bottom part reads "Schematic of the charging/discharging process between two capacitors," but only the "+" charges are drawn to look like the single $\mathrm{T}$ shown in the upper drawing.

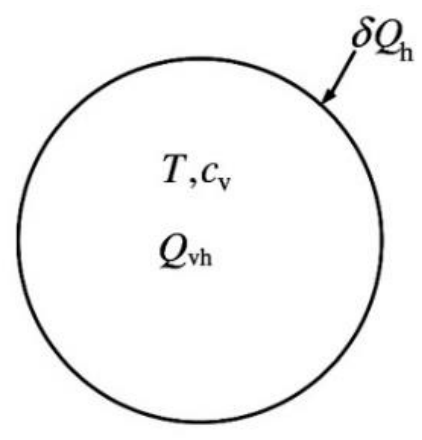

Fig. 1. Spheric thermal capacitor.

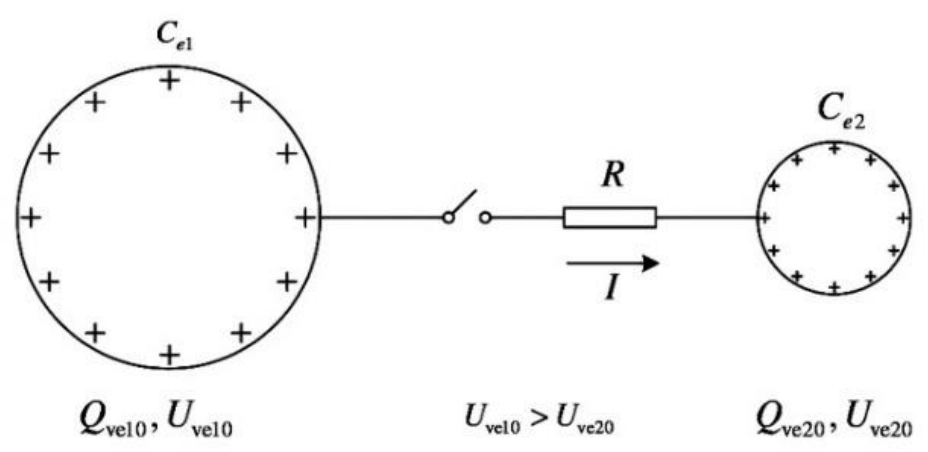

Fig. 2. Schematic of the charging/discharging process between two capacitors.

Figure 3. The first two figures and captions appearing in Ref. [11].

The analogy, if there is one, must be the result of comparing one thermal capacitor with one electric capacitor, not one system with two systems. So, focus on the electrical capacitor on the left: the drawing is only about the discharging that capacitor, not about the charging process that is claimed to be analogous to heating the solid body. A correct drawing would have shown the charging of the capacitor on the left, as claimed in the caption. That would have shown that work transfer happens while the electrical capacitor is being charged, for example, work transfer from a dynamo that forces an electric current to flow into the capacitor, to charge it. 
Pictures do not lie, and heat transfer is not work transfer. Yet, in spite of numerous corrections [12-19], the "entransy" papers that continue to appear [20,21] are worthless; as I explained in [22], "entransy" papers have no basis in reality. Just recently, Awad [23] reviewed this kind of publishing, which is regional not global, and he wrote: "the IHTC16 (Int. Heat Transf. Conf. Beijing 2018), put up a panel discussion of entransy [24]. The first query from the audience was: < If the entransy is useful, can we use entransy in other countries rather than China? > By the way, all the entransy papers at IHTC16 were written by Chinese authors [25-29]."

The atmosphere, as a dissipative heat engine, beats the Carnot efficiency: Several papers are giving the reader the impression that the atmosphere contradicts Carnot. This idea was proven false by Makarieva et al. [30], who showed that a "dissipative engine that feeds on its own dissipation" cannot exist. I showed in Ref. [4] that the confusion is due to the fact that the proponents of the idea [31-33] did not keep the system definition fixed during their evaluation of the heat engine efficiency. Curious is that authors [32,33] that publish after the correction [30] choose to repeat the original claim [31] while saying nothing about the correction [30].

Thermodynamics teaches that dissipative engines exist. All real engines are dissipative. They are everywhere- they are the irreversible engines that keep the Earth spheres moving. The engines that do not exist are the engines driven by the heat input derived from the dissipation of their own work output $[1,7,10]$.

\section{Conclusions}

Students are not taught "discipline" along with their thermodynamics. Perhaps they are taught other things, but as I just showed some of those other things are dead wrong. To see how wrong, take a look at what anonymous authorities post as "thermodynamics" on Wikipedia. Try to correct that, and you find yourself censored. The anonymous agree with each other, as they continue their probabilistic march to reductionism.

Words matter, and pictures do not lie. One word has one sense, a message that conveys to others the mental image that gave birth to that word a very long time ago. Get into the habit of reading dictionaries of the languages in which science was born, developed, and written: Latin, Greek, Italian, French, English, and German. It is essential to understand the terms of any discussion about thermodynamics and entropy.

There is no contradiction between discipline and the freedom to explore new ideas and pose new questions. There is oneness. The scientist who possesses the disciplines is the most free and able to venture into the virgin forest of knowledge. Discipline is empowering and liberating [1].

Funding: This research received no external funding.

Acknowledgments: This article was written during the author's term as recipient of the 2019 Humboldt Research Award. The author thanks Yousef Haseli for contributing many useful and clarifying suggestions during the writing of this manuscript.

Conflicts of Interest: The author declares no conflict of interest.

\section{References}

1. Bejan, A. Freedom and Evolution: Hierarchy in Nature, Society and Science; Springer: New York, NY, USA, 2020. ISBN 978-3-030-34008-7.

2. Bejan, A. Evolution in thermodynamics. Appl. Phys. Rev. 2017, 4, 011305. [CrossRef]

3. Bejan, A. Thermodynamics today. Energy 2018, 160, 1208-1219. [CrossRef]

4. Bejan, A. Thermodynamics of heating. Proc. R. Soc. Math. Phys. Eng. Sci. 2019, 475, 20180820. [CrossRef]

5. Bejan, A. Why the Days Seem Shorter as We Get Older. Eur. Rev. 2019, 1-8. [CrossRef]

6. Bejan, A. Maxwell's Demons Everywhere: Evolving Design as the Arrow of Time. Sci. Rep. $2015,4$. [CrossRef] [PubMed]

7. Bejan, A. Advanced Engineering Thermodynamics, 4th ed.; John Wiley \& Sons Inc: Hoboken, NJ, USA, 2016. ISBN 978-1-119-05209-8. 
8. Bejan, A.; Lorente, S. Design with Constructal Theory; John Wiley \& Sons, Inc.: Hoboken, NJ, USA, 2008. ISBN 978-0-471-99816-7.

9. Reis, A.H. Use and validity of principles of extremum of entropy production in the study of complex systems. Ann. Phys. 2014, 346, 22-27. [CrossRef]

10. Bejan, A. Entropy Generation through Heat and Fluid Flow; Wiley: New York, NY, USA, 1982. ISBN 978-0-47109438-8.

11. Guo, Z.-Y.; Zhu, H.-Y.; Liang, X.-G. Entransy-A physical quantity describing heat transfer ability. Int. J. Heat Mass Transf. 2007, 50, 2545-2556. [CrossRef]

12. Grazzini, G.; Borchiellini, R.; Lucia, U. Entropy versus entransy. J. Non-Equilib. Thermodyn. 2013, 38, $259-271$. [CrossRef]

13. Herwig, H. Do We Really Need “Entransy"? A Critical Assessment of a New Quantity in Heat Transfer Analysis. J. Heat Transf. 2014, 136. [CrossRef]

14. Bejan, A. "Entransy," and Its Lack of Content in Physics. J. Heat Transf. 2014, 136, 055501. [CrossRef]

15. Awad, M.M. Discussion: “Entransy is Now Clear". J. Heat Transf. 2014, 136, 095502-095502-2. [CrossRef]

16. Del Rio Oliveira, S.; Milanez, L.F. Equivalence between the application of entransy and entropy generation. Int. J. Heat Mass Transf. 2014, 79, 518-525. [CrossRef]

17. Manjunath, K.; Kaushik, S.C. Second law thermodynamic study of heat exchangers: A review. Renew. Sustain. Energy Rev. 2014, 40, 348-374. [CrossRef]

18. Grazzini, G.; Rocchetti, A. Thermodynamic optimization of irreversible refrigerators. Energy Convers. Manag. 2014, 84, 583-588. [CrossRef]

19. Sekulic, D.P.; Sciubba, E.; Moran, M.J. Entransy: A misleading concept for the analysis and optimization of thermal systems. Energy 2015, 80, 251-253. [CrossRef]

20. Cheng, X.; Liang, X. Discussion on the analogy between heat and electric conductions. Int. J. Heat Mass Transf. 2019, 131, 709-712. [CrossRef]

21. Yu, Z.-Q.; Wang, P.; Zhou, W.-J.; Li, Z.-Y.; Tao, W.-Q. Study on the consistency between field synergy principle and entransy dissipation extremum principle. Int. J. Heat Mass Transf. 2018, 116, 621-634. [CrossRef]

22. Bejan, A. Comment on "Study on the consistency between field synergy principle and entransy dissipation extremum principle". Int. J. Heat Mass Transf. 2018, 120, 1187-1188. [CrossRef]

23. Awad, M. Comments on "Analysis of heat transfer and irreversibility of ORC evaporator for selecting working fluid and operating conditions". Therm. Sci. 2020, 170. [CrossRef]

24. 16th International Heat Transfer Conference (IHTC 16). Available online: https://www.ihtc16.org/panel.php (accessed on 9 May 2020).

25. Zhao, T.; Hua, Y.-C.; Guo, Z.-Y. The Entransy Based Analysis of the Operation Principle of the Absorption Heat Pump. In Proceedings of the International Heat Transfer Conference 16, Beijing, China, 10-15 August 2018; Begellhouse: Beijing, China; pp. 4237-4244.

26. Hua, Y.-C.; Guo, Z.-Y. Characterizing the Irreversibility of Heat Conduction Process by Entransy and its Dissipation Rate as Lyapunov Functions. In Proceedings of the International Heat Transfer Conference 16, Beijing, China, 10-15 August 2018; Begellhouse: Beijing, China; pp. 2569-2574.

27. Zhang, X.; Li, Z. Entransy of Water Vapor and its Balance Equation for Heat and Mass Transfer Process in the Absorber. In Proceedings of the International Heat Transfer Conference 16, Beijing, China, 10-15 August 2018; Begellhouse: Beijing, China; pp. 5795-5802.

28. Liu, D.; Chen, Q.; He, K.-L.; Chen, X. Simultaneous Optimization of Heat Transfer Processes and Heat Exchanger Networks Based on the Entransy-Based Power Flow Method. In Proceedings of the International Heat Transfer Conference 16, Beijing, China, 10-15 August 2018; Begellhouse: Beijing, China; pp. 4843-4850.

29. He, K.-L.; Chen, Q.; Wang, Y.-F.; Hao, J.-H. Integtated Analysis and Control for the Dynamic Characteristic of Heat Exchanger System Based on Thermal Resistance Method. In Proceedings of the International Heat Transfer Conference 16, Beijing, China, 10-15 August 2018; Begellhouse: Beijing, China; pp. 7899-7906.

30. Makarieva, A.M.; Gorshkov, V.G.; Li, B.-L.; Nobre, A.D. A critique of some modern applications of the Carnot heat engine concept: The dissipative heat engine cannot exist. Proc. R. Soc. Lond. Math. Phys. Eng. Sci. 2010, 466, 1893-1902. [CrossRef]

31. Bister, M.; Renno, N.; Pauluis, O.; Emanuel, K. Comment on Makarieva et al. 'A critique of some modern applications of the Carnot heat engine concept: The dissipative heat engine cannot exist.'. Proc. R. Soc. A Math. Phys. Eng. Sci. 2011, 2125, 1-6. [CrossRef] 
32. Denur, J. The apparent "super-Carnot" efficiency of hurricanes: Nature's steam engine versus the steam locomotive. Am. J. Phys. 2011, 79, 631-643. [CrossRef]

33. Kleidon, A. Thermodynamic Foundations of the Earth System; Cambridge University Press: Cambridge, UK, 2016. ISBN 978-1-139-34274-2. 